\title{
La introducción de los modelos de Simon Vouet en la pintura de finales del siglo xvIII: el ejemplo de Domingo de Rada (1737-1824)
}

\author{
Myriam Ferreira Fernández \\ Universidad Internacional de La Rioja (UNIR)
}

RESUMEN:

la utilización de estampas por parte de pintores para componer sus obras durante la Edad Moderna ha sido estudiada por diferentes investigadores. En general, hay acuerdo en que durante el siglo XVII las estampas más utilizadas eran las basadas en artistas flamencos como Rubens o Van Dyck y que en el siglo xvIII estos artistas fueron desplazados por autores franceses, especialmente Vouet. Sin embargo, existe disensión sobre si hacia finales del siglo xviII esta sustitución había ya tenido lugar o si aún se seguían utilizando de forma generalizada los modelos flamencos. Por ello, ofrecemos el análisis de la colección de estampas y la obra pictórica de un pintor en activo en esa época, Domingo de Rada. Dicho análisis concluye que, aunque Rada tenía gran interés por los autores franceses, la influencia de artistas flamencos siguió siendo muy fuerte tanto en sus estampas como en las composiciones de sus obras.

PALABRAS CLAVE:

estampas, pintura, Domingo de Rada, Simon Vouet, academicismo.

\section{ABSTRACT:}

the use in the Modern Age of engravings by painters for the composition of their works has been studied by different researchers. In general, there is agreement that during the seventeenth century the most commonly used prints were those based on Flemish artists such as Rubens or Van Dyck and that in the eighteenth century these artists were displaced by French authors, especially Vouet. However, there is not agreement about whether by the end of the xvinth century this substitution had already taken place or if the Flemish models were still widely used. Therefore, this paper provides an analysis of the engravings' collection and the pictorial work of a painter in active at that time, Domingo de Rada. This analysis concludes that, although Rada had a great interest on French authors, the influence of Flemish artists was still strong in the engravings he had and in the works he painted.

\section{KEYWORDS:}

engravings, painting, Domingo de Rada, Simon Vouet, academicism. 
La utilización de estampas como forma de inspiración por parte de diferentes artistas ha sido una constante durante la Edad Moderna ${ }^{1}$. Los principales teóricos del arte moderno, como Pacheco, Palomino o Ceán Bermúdez, se referían a esta práctica con un tono despectivo, achacándolo a la falta de imaginación de los pintores y escultores que las utilizaban. Sin embargo, artistas prestigiosos como Gregorio Fernández o Alonso Cano demostraron su interés

Se trata de un tema que ha atraído el interés de numerosos investigadores, destacando obras como CARRETE PARRONDO, Juan, "Una pintura de Rubens grabada por Manuel Salvador Carmona”, en Goya: Revista de arte, 140-141, Madrid, 1977, pp. 140-141; SILVA MAROTO, Pilar, "La influencia del grabado en el arte de la época de Carlos III", en IV Jornadas de Arte: El arte en tiempo de Carlos III, Ediciones Alpuerto, Madrid, 1989, pp. 401-414; ANGULO, E. et al., "Las estampas de los Sadeler como transmisoras de modelos iconográficos en la pintura flamenca del siglo XVII", en Goya: Revista de arte, 251, Madrid, 1996, pp. 265-275; NAVARRETE PRIETO, Benito, La pintura andaluza del siglo XVII y sus fuentes grabadas, Fundación de apoyo a la historia del arte hispánico, Madrid, 1998; RODRÍGUEZ RUIZ, Delfín, "De pintura y escultura. Tratados y colecciones de estampas", en La Real Biblioteca Pública, 17111760, de Felipe V a Fernando VI, Biblioteca Nacional de España, Madrid, 2004, pp. 349-358; NAVARRETE PRIETO, Benito (et al.), Fuentes y modelos de la pintura barroca madrileña, Editorial Arco/Libros, Madrid, 2008; PORTÚS PÉREZ, Javier, "Pinturas y estampas en el barroco andaluz", en La imagen reflejada: Andalucía, espejo de Europa, Junta de Andalucía - Consejería de cultura, Sevilla, 2008, pp. 24-41; VÉLEZ CHAURRI, José Javier, "La estampa rubeniana en la escultura barroca del País Vasco", en Estudios de Historia del Arte en memoria de la profesora Micaela Portilla, Arabako Foru Aldundia - Diputación Foral de Álava, Vitoria, 2008, pp. 223-236; MORENO CUADRO, Fernando, "Rubens y el Carmelo. Entre la estampa de invención y la de reproducción", en Boletín del Museo e Instituto Camón Aznar, 106, Zaragoza, 2010, pp. 153-180, en https://delaruecaalapluma.files.wordpress.com/2014/09/ rubens-y-el-carmelo.pdf; REQUENA BRAVO DE LAGUNA, José Luis, "Nuevas fuentes grabadas en la obra de Juan de Sevilla y Alonso Cano”, en Atrio, 17, Sevilla, 2011, pp. 5-16, en https://www.upo.es/revistas/ index.php/atrio/article/download/543/399; PORTÚS PÉREZ, Javier, "Estampas, artistas y gabinetes. Breve historia del grabado: El poeta, c. 1620-1621, de Jusepe de Ribera”, en Revista de la Fundación Juan March, 417, Madrid, 2013, pp. 2-8; GIMILIO SANZ, David, "La transmisión de los modelos. Del grabado europeo a la pintura valenciana del Museo de Bellas Artes" en Ars Longa, 24, Valencia, 2015, pp. 135-151, en https://dialnet.unirioja.es/servlet/articulo?codigo $=5432557$ torden=0Ctinfo=link; VÉLEZ CHAURRI, José Javier y ECHEVERRÍA GOÑI, Pedro Luis, "Identificación de una serie de grabados rubenianos como modelo de los relieves de la sillería de Lanciego (Álava)", en BSAA Arte, 82, Valladolid, 2016, pp. 185-203, en https://dialnet. unirioja.es/descarga/articulo/5866522.pdf. por el uso de estampas, acabando por asentar esta práctica. Para que las escenas y personajes resultaran más innovadores, era frecuente recurrir a estampas de artistas extranjeros, que podían ser flamencos, franceses, italianos 0 españoles. A lo largo de la Edad Moderna veremos cómo la influencia de unos y otros irá creciendo o disminuyendo al ir avanzando las centurias.

En efecto, durante el siglo XVI había una preferencia por artistas manieristas de procedencias variadas, como Durero o Marco Antonio Raimondi, aunque predominaban los grabadores flamencos y holandeses como Cornelis Cort, los Wierix o Goltzius ${ }^{2}$. Durante el siglo XVII, los artistas más influyentes pasarán a ser artistas flamencos como Van Dyck y, sobre todo, Rubens, gracias a las estampas realizadas por grabadores como Lucas Vorsterman, Paulus Pontius, Schelte a Bolswert y Theodor Galle 3 . Por su parte, ya desde finales del siglo XVII y durante todo el siglo XVIII, las estampas más difundidas serán las basadas en autores franceses, destacando especiales las inspiradas en obras de Simon Vouet (1590-1649), el autor francés más imitado durante esta centuria ${ }^{4}$. La influencia de Vouet en España a través de las estampas se debe a diversas razones. Por un lado, la calidad de los grabados franceses llegados a España será muy superior a la de los grabados españoles y mejor también que la de los grabados flamencos. Por otro lado, la Corte iba mostrando una creciente preferencia por los modelos franceses desde la llegada de los Borbones al poder. Y a todo ello hay que añadir que la pervivencia en el entorno cortesano de un cierto clasicismo gracias a la importancia de las colecciones reales que hará que la figura de Vouet resulte especialmente interesante

VÉLEZ CHAURRI, José Javier, “La estampa rubeniana”, opus cit., p. 224.

3 VÉLEZ CHAURRI, José Javier, "La estampa rubeniana”, opus cit., p. 225; ESCUÍN GUINEA, María Jesús, "La pintura flamenca barroca en La Rioja", en Historia del arte en La Rioja 4, Fundación Cajarioja, Logroño, 2005, pp. 209-224.

4 SILVA MAROTO, Pilar, "La influencia del grabado", opus cit., p. 401; JIMÉNO, Frédéric, "El papel de Francia en la pintura aragonesa del siglo xvIII", en Boletín del museo e instituto Camón Aznar, vol. LXXIV, Zaragoza, 1998, p. 136; JIMÉNO, Frédéric, “Des modèles français dans l'Espagne de Charles II (1665-1700). Origins et émergence d'un nouveau goût en peinture", en El arte español entre Roma y París (siglos XVIII y XIX): Intercambios artísticos y circulación de modelos, Casa de Velázquez, Madrid, 2014, pp. 191-210. 
porque en este pintor el estilo barroco francés se hallaba matizado por la influencia clasicista adquirida durante su estancia en Italia.

La influencia de los modelos de Vouet a través de estampas llegadas a España ha sido ampliamente estudiada por autores como Luna o Jiméno ${ }^{5}$. Para este último autor, "Simon Vouet es el artista francés mejor difundido por el grabado en la pintura española de los siglos XVII y xviII" alargándose su influencia "de manera regular hasta las guerras napoleónicas”. De hecho, cita ejemplos de artistas académicos, como Manuel Salvador Carmona, Francisco Bayeu o Francisco de Goya que recogen la influencia de Vouet y su círculo ya entrado el siglo XIX. E insiste en que estos modelos franceses "van a substituir los grabados flamencos y neerlandeses en los inventarios de bienes de artistas del siglo XVIII"'.

Sin embargo, a pesar de la afirmación de Jiméno, no en todos los lugares fue general esta sustitución de los modelos flamencos por los franceses en el siglo xvIII. Refiriéndose al País Vasco, Vélez Chaurri comenta que la influencia de estampas de autores flamencos, en especial de Rubens, no solo no desaparece a finales del siglo XVIII sino que es más fuerte que nunca: "es en la segunda mitad de esta centuria (siglo xvIII) cuando estos grabados son utilizado con mayor profusión en las tallas de conjuntos rococós y neoclásicos salidas de las gubias de Luis Salvador Carmona, José y Francisco Sierra o escultores locales como Mauricio Valdivielso o Juan Bautista Mendizábal. Esta situación impli-

\footnotetext{
LUNA FERNÁNDEZ, Juan José, “Trasuntos pictóricos y referencias escritas de obras de Simon Vouet en colecciones españolas", en Archivo español de arte, 63.251, Madrid, 1990, pp. 465-470; JIMÉNO, Frédéric, "El papel de Francia”, opus cit., pp. 140-141; JIMÉNO, Frédéric, "Algunos modelos franceses en la pintura española del siglo XVII: Nicolas Poussin y Claude Vignon", en Butlleti de la Reial Acadèmia Catalana de Belles Arts de Sant Jordi, 14, Barcelona, 2000, pp. 65-83, en https://www.raco.cat/index.php/ButlletiRACBASJ/ article/view/219314/329737; JIMÉNO, Frédéric, "La influencia de Simon Vouet en Goya y sus contemporáneos", en Goya y el Palacio de Sobradiel, Gobierno de Aragón-Departamento de educación, cultura y deporte, Zaragoza, 2006, pp. 167-211. Ver también JIMÉNO, Frédéric, "Goya y Francia, un ensayo sobre la recepción del gusto francés en la obra de Francisco de Goya”, en Artigrama, 25, Zaragoza, 2010, pp. 79-101, en https://www.unizar.es/artigrama/pdf/25/2monografico/05.pdf; REQUENA BRAVO DE LAGUNA, José Luis, "Nuevas fuentes grabadas...", opus cit., p. 8-9.

6 JIMÉNO, Frédéric, "Algunos modelos franceses", opus cit., p. 68-70.
}

ca que el verdadero carácter barroco de nuestra escultura de los siglos XVII y XVIII no la poseen las obras del mil seiscientos ni de los primeros cuarenta años de la siguiente centuria, sino las tallas y los relieves académicos de la segunda mitad del siglo XvIII"

Para ofrecer un testimonio en favor de una u otra teoría, se presenta en este artículo el inventario de bienes de un pintor, Domingo de Rada, originario de La Rioja aunque en activo también en el País Vasco y Navarra durante la segunda mitad del siglo xviII y el primer cuarto del siglo XIX. Rada, aunque no se formó en un ámbito académico, sí que desempeñó labor docente en instituciones como la Escuela de Dibujo de Bilbao o la de Logroño y estuvo en contacto con instituciones ligadas al pensamiento ilustrado como la Real Sociedad Bascongada de Amigos del País. Además, en su caso contamos con un documento de gran interés para acercarnos a sus referentes artísticos: su inventario de bienes, realizado en 1804, y que contaba con una colección de más de 300 estampas, todas ellas enunciadas por su título y/o autor y tasadas por el propio Rada y por su hijo, también pintor ${ }^{8}$. Por lo tanto, el objetivo de este trabajo es analizar dicho inventario, así como la obra pictórica de dicho pintor e identificar tanto la influencia francesa, en especial de Vouet, como la influencia flamenca presente en ellos.

\section{El pintor Domingo de Rada}

Domingo de Rada nació en Santo Domingo de la Calzada (La Rioja) en $1737^{9}$. Pertenecía a una familia dedicada a la pintura durante generaciones, en la que se incluía su abuelo, José de Rada, su padre, Eugenio de Rada, y varios tíos y hermanos. La familia pertenecía al estado noble y tenía una gran consideración por su trabajo,

\footnotetext{
VÉLEZ CHAURRI, José Javier, “La estampa rubeniana”, opus cit., p. 223.

8 Archivo Histórico Provincial de La Rioja (AHPLR), Protocolos notariales, Logroño, leg. 1135, 1804, fol. 204r.$214 \mathrm{v}$. La existencia y localización de este inventario fue dada a conocer por Martínez Ocio en el artículo MARTÍNEZ OCIO, María Jesús, "La Escuela de Dibujo, Matemáticas y Música de Logroño”, en Aspectos menos conocidos del arte riojano (1997-1999), Ateneo Riojano, Logroño, 2000, pp. 147-172.

9 GUTIERREZ PASTOR, Ismael, "La pintura del siglo XVIII en La Rioja”, en Historia del arte en La Rioja 4, Fundación Cajarioja, Logroño, 2005, pp. 357-429.
} 
que Eugenio definía, ya en 1752, como "el Arte liberal de Pintor de Profesión" ${ }^{10}$.

Desde muy joven, y en compañía de su familia, Domingo fue trabajando en localidades riojanas y navarras como el Villar de Arnedo, Aldeanueva de Cameros, Logroño, Arguedas, San Torcuato o Haro, en su mayor parte realizando dorados y policromía de retablos, aunque también fue el autor de la pintura mural de una capilla en Arguedas o el Monumento de San Torcuato, ambos no conservados hoy en dia ${ }^{11}$. Poco después, en 1764, le llegó un encargo destacado en Calahorra: realizar las pinturas murales de la Iglesia de Santiago el Real y de la Catedral de Santa María ${ }^{12}$. Como en septiembre de 1763 había contraído matrimonio en Haro con Celestina Martínez de Ontiveros, la familia se trasladó a Calahorra, instalando allí su residencia por más de 15 años. En Calahorra fueron naciendo los hijos del matrimonio: Antonio Gil Sandalio, nacido en 1764; Manuel Ildefonso, nacido en 1766; Anselmo José, nacido en 1768; María Paula Ildefonsa, nacida en 1770; Antonio Casimiro, nacido en 1772; Miguel Antonio, nacido en 1773 y Teodoro Domingo, na-

10 AHPLR, Catastro de Ensenada, Memoriales de Seglares, Santo Domingo de la Calzada, 1752, vol. 639, núm. 402. 1 GUTIÉRREZ PASTOR, Ismael, "La pintura del siglo XVIII”, opus cit., pp. 402-403; MOYA VALGAÑÓN, José Gabriel, Inventario artístico de Logroño y su provincia, Instituto de Estudios Riojanos, Logroño, 1975, I, 236; II, 306; SÁNCHEZ PORTILLO, Paloma, "Nuestra Señora de La Vega en Haro (La Rioja): decoración de la basílica en los siglos XVII-XVIII", en Berceo, 140, Logroño, 2001, p. 123, en https://dialnet.unirioja.es/descarga/ articulo/61959.pdf.

12 LECUONA, Manuel de, "La parroquia de Santiago, de Calahorra”, en Berceo, 25, Logroño, 1952, pp. 601-634, en https://dialnet.unirioja.es/descarga/articulo/61141. pdf; MATEOS GIL, Ana Jesús, "Las urnas relicario de San Emeterio y San Celedonio de la catedral de Calahorra" en Kalakorikos: Revista para el estudio, defensa, protección y divulgación del patrimonio histórico, artístico y cultural de Calahorra y su entorno, 5, Calahorra, 2000, pp. 105-124, en https://dialnet.unirioja.es/ descarga/articulo/192205.pdf; MATEOS GIL, Ana Jesús, "La influencia artística de Juan Miguel Mortela en la catedral de Calahorra", en Kalakorikos: Revista para el estudio, defensa, protección y divulgación del patrimonio histórico, artístico y cultural de Calahorra y su entorno, 1, Calahorra, 1996, pp. 69-84, en https://dialnet.unirioja.es/descarga/articulo/192110.pdf; MIGUEL REBOLES, María Teresa de, "Lectura de dos altares de San José en Calahorra”, en Kalakorikos: Revista para el estudio, defensa, protección y divulgación del patrimonio histórico, artístico y cultural de Calahorra y su entorno, 15, Calahorra, 2010, p. 440, en https://dialnet. unirioja.es/descarga/articulo/3347504.pdf. cido en $1774^{13}$. Solo dos (Manuel y Anselmo) alcanzaron la edad adulta.

En Calahorra, Rada y su familia entraron en contacto con un pintor que iba adquiriendo un prestigio cada vez mayor en La Rioja: José Bejes. Bejes, natural de Potes (Cantabria), se había instalado en esta región tras una estancia en Italia, que le había proporcionado un estilo rococó suelto y colorido, diferente del estilo, más seco, de la familia Rada. A pesar de esta diferencia, los Rada y Bejes se asociaron para acometer algunas de las obras de Calahorra ${ }^{14}$.

Esta asociación resulta interesante porque, hacia 1774, Bejes se trasladó a Vizcaya, donde realizó diferentes encargos, entre ellos la policromía de dos retablos en Durango ${ }^{15}$. También sabemos que, en ese tiempo, Bejes tuvo contacto con la Escuela de Dibujo de Bilbao, en la que estaba matriculado su hijo ${ }^{16}$. Estos datos resultan interesantes porque, justo cuando tuvo el regreso de Bejes a La Rioja, en 1780, Domingo de Rada se trasladó a Bilbao con su familia. Podemos suponer que tal vez Bejes comunicó a Rada alguna posibilidad de encargos en Bilbao y que ése fuera el motivo de su marcha.

Rada permaneció en Bilbao más de 20 años, desempeñando diversas tareas, como la decoración pictórica del salón y oratorio del Ayuntamiento, bajo la supervisión de Luis Paret y Alcázar (1785), así como la pintura mural del edificio del Teatro Coliseo Nuevo de Bilbao, dos obras que, desdichadamente, no se conservan actualmente ${ }^{17}$. También adquirió cierto prestigio como

13 Archivo de la Catedral de Calahorra (ACCal), Bautizados 9, fol. 141, 179, 239, 286, 353, 398 y Bautizados 10, fol. 17. Agradecemos a don Ángel Ortega, archivero de la Catedral de Calahorra, habernos facilitado esta información.

14 GUTIÉRREZ PASTOR, Ismael, "La colección de pinturas del monasterio de San Millán de la Cogolla”, en Cuadernos de investigación: Historia, 10.2, Logroño, 1984, pp. 129-148, en https://dialnet.unirioja.es/descarga/ articulo/81597.pdf; TORRALBA SORIANO, Federico, "José Bexes y los decoradores barrocos españoles", en Berceo, 34, Logroño, 1955, pp. 57-78.

15 ZORROZUA, Julen, El retablo neoclásico en Bizkaia, Departamento de Cultura, Bilbao, 2003, p. 71.

16 ECHEVERRÍA GOÑI, Pedro Luis, "Los monumentos o perspectivas en la escenografía del siglo XVIII de las grandes villas de la Ribera estellesa”, en Príncipe de Viana, 51.190, Pamplona, 1990, pp. 517-532, p. 520, en https://dialnet.unirioja.es/descarga/articulo/15875. pdf; ZORROZUA, Julen, El retablo neoclásico, opus cit., p. 26.

17 LABEAGA MENDIOLA, Juan Cruz, "Algunas noticias sobre la estancia del pintor Luis Paret y Alcázar en Bilbao", en Noveno Congreso de Estudios Vascos: An- 
pintor decorador, encargándose de la decoración pictórica de fachadas de viviendas "al temple con colas y las paredes secas"18. González Santos indica que lo más probable es que la técnica utilizada fuera "la de la encáustica, (temple con base de colas y ceras), puesta de moda a partir de los descubrimientos arqueológicos de las ciudades romanas de Pompeya y Herculano" ${ }^{19}$.

Además de estas obras de carácter civil, realizó labores de policromía y dorado para obras religiosas de diversas localidades vizcaínas como Lezama, Maruri o Busturia-Axpe ${ }^{20}$. Y también siguió aceptando encargos en La Rioja, como el dorado de dos retablos en la iglesia de Santo Tomás de Haro (La Rioja) en $1788^{21}$.

A pesar de toda esta actividad, la principal tarea de Rada en Bilbao fue ejercer como maestro en la Escuela de Dibujo de esta ciudad, impulsada por la Sociedad Bascongada de Amigos del País ${ }^{22}$. Domingo era el único profesor de la

tecedentes próximos de la sociedad vasca actual. Siglos XVIII y XIX, Eusko-Ikaskuntza, San Sebastián, 1984, pp. 449-450, en http://www.euskomedia.org/PDFAnlt/ congresos/09/09449451.pdf; BILBA0 SALSIDUA, Mikel, "Arquitectura teatral en Bilbao durante los siglos xIX y xx. De los lugares para la memoria a los espacios recuperados", en Bidebarrieta: Revista de humanidades $y$ ciencias sociales de Bilbao, 23, Bilbao, 2012, p. 39, en http://www.ehu.eus/ojs/index.php/Bidebarrieta/article/ view/18753/16713. Este teatro fue construido en 1799 en la calle Ronda y arrasado por un incendio en 1816.

18 JOVELLANOS, Gaspar Melchor, Obras completas VIII. Diario, $3^{\circ}$. Cuadernos VII, Conclusión y VIII al XIV (19 agosto 1797-6 marzo 1810) (edición crítica de María Teresa Caso Machicado; notas y selección de ilustraciones de Javier González Santos), Ayuntamiento de Gijón - Instituto Feijoo de Estudios del Siglo XVIII - KRK Ediciones, Gijón, 2011, p. 98.Ver ASPIAZU PINED0, Roberto, "Las casas pintadas de Bizkaia", en Narria: estudios de artes y costumbres populares, 61, Madrid, 1993, pp. 14-24, en https://repositorio.uam.es/bitstream/handle/10486/8380/45310_3.pdf?sequence $=1$.

19 JOVELLANOS, Gaspar Melchor, Obras completas, opus cit., p. 98.

20 ZORROZUA, Julen, "Las artes figurativas en el Neoclásico: estado de la cuestión", en Ondare, 21, Vitoria, 2002, p. 69, en http://docplayer.es/39964167-Las-artes-figurativas-en-el-neoclasicismo-vasco-estado-dela-cuestion.html; ECHEVERRÍA GOÑI, Pedro Luis, "Los monumentos o perspectivas”, opus cit., pp. 517-532; GUTIÉRREZ PASTOR, Ismael, "La pintura del siglo XVIII”, opus cit., pp. 357-429. Cfr. JOVELLANOS, Gaspar Melchor, Obras completas, opus cit., p. 98; ZORROZUA, Julen, El retablo neoclásico, opus cit., p. 47.

${ }^{21}$ CAÑAS MARTÍNEZ, Yolanda, "Las artes en Haro durante el siglo XVIII a partir de las fuentes documentales", en Berceo, 112-113, Logroño, 1987, p. 66, en https:// dialnet.unirioja.es/descarga/articulo/61717.pdf.

22 REAL SOCIEDAD BASCONGADA DE LOS AMIGOS DEL PAÍS, Extractos de las juntas celebradas por la Real Sociedad Bascongada de los Amigos del País, Real Socie- escuela, y su trabajo consistía en enseñar los fundamentos del dibujo a los alumnos, que en 1796 llegaron a ser $95^{23}$. El puesto le granjeaba "trescientos ducados y casa" 24.

El hecho de que Rada trabajara para la Sociedad Bascongada posiblemente le facilitó el contacto con los ambientes ilustrados de la ciudad, ligados a dicha Sociedad. Conocemos su cercanía con familias como los Gortázar, los Urdaibay y los Mazarredo ${ }^{25}$, tres familias que además formaban parte de la elite económica de Bilbao $^{26} \mathrm{y}$ que estaban vinculadas a la Bascongada: un Mazarredo, por ejemplo, era uno de los directores responsables de la Escuela de Dibujo de Bilbao. Estos personajes tenían trato con otros ilustrados del país, como Gaspar Melchor de Jovellanos, quien fue invitado a comer a casa de los Urdaibai en 1797 y conoció allí a Domingo de Rada, a quien consideró un pintor "con bastante gracia y mérito" ${ }^{27}$. Esta opinión de Jovellanos debía de ser compartida por otros personajes, ya que Rada parece haber gozado de cierto prestigio en la ciudad. Una prueba es que fueron varias las veces que fue requerido para actuar como perito experto en la realización de diversos inventarios: en el de Manuel de Lijarraga en 1783, en el de Magdalena de Ugarte en 1788, en el de José Domingo Gortázar en 1790, en un cajón de

dad Bascongada de los Amigos del País, Vitoria, 1783; RUIZ DE AEL, Mariano J., La ilustración artística en el País Vasco: la Real Sociedad Bascongada de Amigos del País y las Artes, Diputación Foral de Álava- Departamento de Cultura, Vitoria-Gasteiz, 1993, p. 27 y 59; Z0RROZUA, Julen, El retablo neoclásico, opus cit., p. 26.

23 GUTIÉRREZ PASTOR, Ismael, "La pintura del siglo XVIII", opus cit., p. 405.

24 JOVELLANOS, Gaspar Melchor, Obras completas, opus cit., p. 98.

25 JOVELLANOS, Gaspar Melchor, Obras completas, opus cit., p. 98.

26 RUIZ DE AEL, Mariano J., La ilustración artística, opus cit.; BASURTO, Román, "Linajes y fortunas mercantiles de Bilbao del siglo XVIII", en Itsas Memoria. Revista de Estudios Maritimos del País Vasco, 4, San Sebastián, 2003, pp. 343-356, en http://um.gipuzkoakultura.net/ pdf/09\%20BASURTO.pdf; IMÍZCOZ, José María y CHAPARRO, Álvaro, "Los orígenes sociales de los ilustrados vascos”, en Ilustración, ilustraciones, Real Sociedad Bascongada de los Amigos del País-Sociedad Estatal de Conmemoraciones Culturales, Donostia-San Sebastián, vol. 2, pp. 993-1027, https://addi.ehu.es/bitstream/ handle/10810/11243/IMIZCOZ\%2c\%20JM\%20-020 Origenes $\% 20$ sociales $\% 20 \mathrm{de} \% 201$ os\%20Ilustrados $\% 20$ vascos.pdf? sequence $=1$ tisAllowed $=\mathrm{y}$.

27 JOVELLANOS, Gaspar Melchor, Obras completas, opus cit., p. 98. Rada se encontraba en la casa porque estaba pintando "la casa de San Nicolás, construida por el abuelo de Lope García Mazarredo, Ventura Gómez de la Torre, y donde vivía con toda su familia” (Ibídem). 
Francisco Nabrich en 1790 y en el inventario de bienes de Antonio Sarria ${ }^{28}$.

Domingo había viajado a Bilbao acompañado de su familia. En esta ciudad tuvo lugar el fallecimiento de su esposa, Celestina, quedando Rada al cargo de sus hijos, Manuel y Anselmo. Ambos acudieron como alumnos a la Escuela de Dibujo ${ }^{29}$, aunque solo Anselmo finalizó su formación artística ${ }^{30}$ : permaneció en la Escuela de Bilbao desde 1782 a 1792, donde ganó varios premios en 1782 y $1784^{31}$, y marchó después a la Real Academia de Bellas Artes de San Fernando de Madrid (1792-1796) ${ }^{32}$. A su regreso a Bilbao, se convirtió en activo ayudante de su padre, incluso a pesar de que, al parecer, el joven pintor era sordo ${ }^{33}$.

Hacia 1804 la Escuela de Dibujo de Bilbao cerró con la idea de impulsar otra más amplia desde el Consulado ${ }^{34}$. Es posible que fuera por entonces cuando Domingo regresó a Logroño, posiblemente acompañado de su segunda esposa, María Jesús de Miranda y del hijo nacido en este matrimonio, Saturnino ${ }^{35}$. También su hijo

${ }_{28}$ GÓMEZ GÓMEZ, Agustín, "El coleccionismo en el Bilbao de finales del siglo xvIII: el caso de la familia Gortazar", en Actas del II Symposium: Bilbao: 700 años de memoria. Arte, patrimonio monumental y ciudad, Bidebarrieta, Bilbao, 1997, pp. 116-117, en http:// www.ehu.eus/ojs/index.php/Bidebarrieta/article/viewFile/18215/15803; Archivo Histórico Foral de Bizkaia (AHFB), JCR 4281/003; JCR0293/017; JCR0190/018 y JCR1808/001.

29 RUIZ DE AEL, Mariano J., La ilustración artística, opus cit., p. 26.

30 El mayor, Manuel, abandonó la Escuela para estudiar Leyes, llegando a desempeñar diversos cargos políticos en toda España. PALACIOS RAMOS, Rafael, "Trayectoria profesional de los Alcaldes Mayores de Santander (1736-1833)", en Altamira: Revista del Centro de Estudios Montañeses, 85, Santander, 2014, pp. 81-82.

31 JOVELLANOS, Gaspar Melchor, Obras completas, opus cit., p. 98; RUIZ DE AEL, Mariano J., La ilustración artística, opus cit.

32 "Nov[iemb]re. (...) En 27 Anselmo de Rada y Martínez nat[ura]l de Calahorra de 25 a[ño]s" (Archivo de la Real Academia de Bellas Artes de San Fernando (ARABASF), Libros de matrícula de la Real Academia de Bellas Artes de San Fernando (1752-1815), leg. 3-301, fol. 6v.) Cfr. PARDO CANALÍS, Enrique, Los registros de matrícula de la Academia de San Fernando de 1752 a 1815, Consejo Superior de Investigaciones Científicas - Instituto “Diego Velázquez”, Madrid, 1967, p. 194.

33 JOVELLANOS, Gaspar Melchor, Obras completas, opus cit., p. 98.

34 RUIZ DE AEL, Mariano J., La ilustración artística, opus cit., p. 201; ZORROZUA, Julen, El retablo neoclásico, opus cit., p. 26.

35 Ni el matrimonio entre Domingo y María Jesús ni el nacimiento de Saturnino figuran en los registros de Santa María de Palacio, donde Domingo fue parro-
Anselmo, que había contraído matrimonio con una joven vasca de buena familia, María Manuela de Areche $^{36}$, se instaló en Logroño con su familia. Fue en esos momentos cuando Anselmo solicitó a su padre que realizara el inventario al que nos hemos referido, para diferenciar los bienes que correspondían a los hijos de cada matrimonio. Poco después falleció María Jesús, quedando Domingo viudo por segunda vez y al cargo de su hijo Saturnino, aún muy pequeño ${ }^{37}$.

En 1814, a pesar de su avanzada edad, Domingo fue nombrado junto con su hijo Anselmo profesor de la recién creada Escuela de Dibujo de Logroño, puesta en marcha por el Ayuntamiento de la ciudad ${ }^{38}$. Tal vez se acudió a los Rada por su experiencia en la Escuela de Dibujo de Bilbao y la formación académica de Anselmo. Sin embargo, la actividad docente de estos pintores en la Escuela de Logroño fue breve, ya que solo un año después fueron sustituidos por un nuevo profesor. La razón esgrimida fue que la Escuela de Dibujo deseaba que la propia Academia de San Fernando nombrara al nuevo profesor, probablemente para granjearse la aprobación de la Real Academia, que veía con recelo la creación de esta Escuela por iniciativa particular.

Ante estas circunstancias, Anselmo de Rada regresó a Bilbao ${ }^{39}$, mientras Domingo permanecía viviendo en Logroño, en compañía de su hijo pequeño, Saturnino. Su domicilio estaba en la calle de Zapaterías y eran parroquianos de la cercana iglesia de Santa María de Palacio ${ }^{40}$. Falleció el 29 de mayo de 1824, a los 88 años de edad ${ }^{41}$.

quiano en Logroño. Por eso, cabe suponer, aunque no podamos confirmarlo, que ambos se produjeron antes del traslado a la ciudad.

36 CÁRDENAS PIERA, Emilio y CADENAS Y VICENT, Vicente, Caballeros de la Orden de Santiago, siglo XVIII. Volumen 5, Ediciones Hidalguía, Madrid, 1994, 128; Archivo Histórico Diocesano de Logroño (AHDL), Bautizados de Santa María de Palacio de Logroño 12 (1787-1809), fol. 232 v. y 324 r.

37 AHPLR, Protocolos notariales, Logroño, leg. 1136, 1806 , fol. 210r.-211v. Este testamento fue realizado hacia 1806 debido a una enfermedad le hizo temer por su vida, aunque se acabó recuperando.

38 MARTÍNEZ OCIO, María Jesús, "La Escuela de Dibujo", opus cit., pp. 147-172.

39 AHFB, Consulado, 0661/015 y 0661/020. Allí opositó en 1821 a una plaza de profesor de Dibujo y a otra de profesor interino de Arquitectura del Consulado de Bilbao, siendo nombrado para ambos puestos.

40 AHDL, Libro de Parroquianos de Santa María de Palacio de Logroño (1806-1822), s/f.

${ }^{41}$ AHDL, Libro de Finados de Santa María de Palacio de Logroño 7 (1824-1839), fol. 3 r. En su partida de de- 
2. Análisis del inventario de estampas de Domingo de Rada

Como indicábamos, el inventario de bienes de Domingo de Rada se realizó en 1804, consignándose en él todo su ajuar doméstico, libros y materiales propios de su oficio, así como una colección de más de 300 estampas ${ }^{42}$. No debían ser estampas de gran calidad teniendo en cuenta la escasa tasación que recibieron (entre 1 y 4 reales en su mayoría) pero muestran una gran variedad de tendencias.

El inventario presenta 321 registros de estampas, aunque algunos incluyen conjuntos de varios grabados, libros, etc. Solo en 143 de estos registros se indica el autor de la obra en que se basó la estampa. El recuento de los mismos muestra que 63 grabados estaban basadas en obras de autores franceses (fig. 1). De ellos, Simon Vouet es el autor más citado en el inventario, con un total de 26 estampas. Además, las estampas de Vouet que Rada posee presentan una gran variedad de temáticas: son grabados de tipo académico (Cabeza de cartilla, Un escorzo, Galería), tema religioso (Eliseo, Degollación de los inocentes, Verónica, Sagrada Familia, Sepulcro, San Francisco de Paula, Crucifijo, El hallazgo de Moisés, la Presentación del Niño, Nuestra Señora, Asunción) y mitológico (Venus, Neptuno, Alcides). Es significativo que en la mitad de los grabados de Vouet solo se indica el autor y no el tema, lo que indica que el valor de esas estampas radicaba en el autor en el que se basaban, siendo una muestra del prestigio de Vouet.

Por su parte, la influencia flamenca también es abundante en el inventario: hay 44 estampas basadas en obras de autores flamencos, concentrándose, sin embargo, en un número pequeño de artistas, solo seis. De todos modos, es significativo que tres de esos artistas (Van Dyck, Rubens y Goltzius) tengan cada uno 10 o más estampas en la colección de Rada, el número más alto después de Vouet.

El resto de estampas del conjunto se basan en obras de artistas italianos y españoles. Es interesante señalar que la mayor parte de los autores franceses citados estaban ligados a la Academia

función se indicó que Domingo había hecho un nuevo testamento antes de morir. Sin embargo, esta escritura no se conserva actualmente en el Archivo Histórico Provincial de La Rioja.

42 AHPLR, Protocolos notariales, Logroño, leg. 1135, 1804, fol. 204r.-214v. francesa, al igual que varios de los autores españoles (Goya, Casanova, Maella y Paret) estaban ligados a la Real Academia de San Fernando. Sin embargo, esto no significa que la colección de Rada muestre un interés destacado por los artistas academicistas, ya que solo una parte de la colección está dedicada a artistas cronológicamente cercanos a él: solo un tercio de las estampas están realizadas por autores que vivieron en el siglo xvIII, mientras que más de la mitad vivieron durante el siglo XVII.

La antigüedad de los modelos de Rada se podría explicar teniendo en cuenta que parte de esta colección de estampas debió de heredarla de su familia, con larga tradición pictórica, como ya hemos indicado. Por lo tanto, para definir cuáles de estos modelos realmente eran valoradas por Rada, se podría plantear la cuestión de cuáles de estas estampas utilizó como inspiración en su obra pictórica.

\section{Análisis de los modelos pictóricos de Domingo de Rada}

Los estudios que han prestado atención a la obra pictórica de Rada citan únicamente tres conjuntos conservados hoy en día y que representen temas figurativos, más allá de un carácter simplemente decorativo. Estos tres conjuntos son: las pinturas murales de la capilla de San Juan Bautista en la Catedral de Santa María de Calahorra (La Rioja) (hacia 1774), las cuatro pechinas de la iglesia de Santiago también en Calahorra, que representan a los cuatro Evangelistas (hacia 1775), y los lienzos situados en los retablos colaterales de la iglesia parroquial de Busturia-Axpe (Vizcaya) (hacia 1792) ${ }^{43}$.

La influencia de las estampas de Rada en estas pinturas es bastante perceptible. En las pechinas de Santiago de Calahorra encontramos uno de los diseños de Simon Vouet: la imagen de San Juan Evangelista está inspirada en un cuadro de Vouet que representa a Alcides o Hércules arengando al pueblo, grabado por $\mathrm{M}$. Dorigny en $1638^{44}$, y recogida en el inventario de Rada como: “187.1. Alcides de Bobet. 001 1/2"

43 MATEOS GIL, Ana Jesús, "La influencia artística”, opus cit., p. 76; GUTIÉRREZ PASTOR, Ismael, "La pintura del siglo XVIII", opus cit., p. 405; ZORROZUA, Julen, El retablo neoclásico, opus cit., p. 69

44 DUMESNIL, Robert, Le peintre-graveur franc ais: ou Catalogue raisonné des estampes gravées par les peintres et les dessinateurs de l'école franc aise. Tomo 4, 


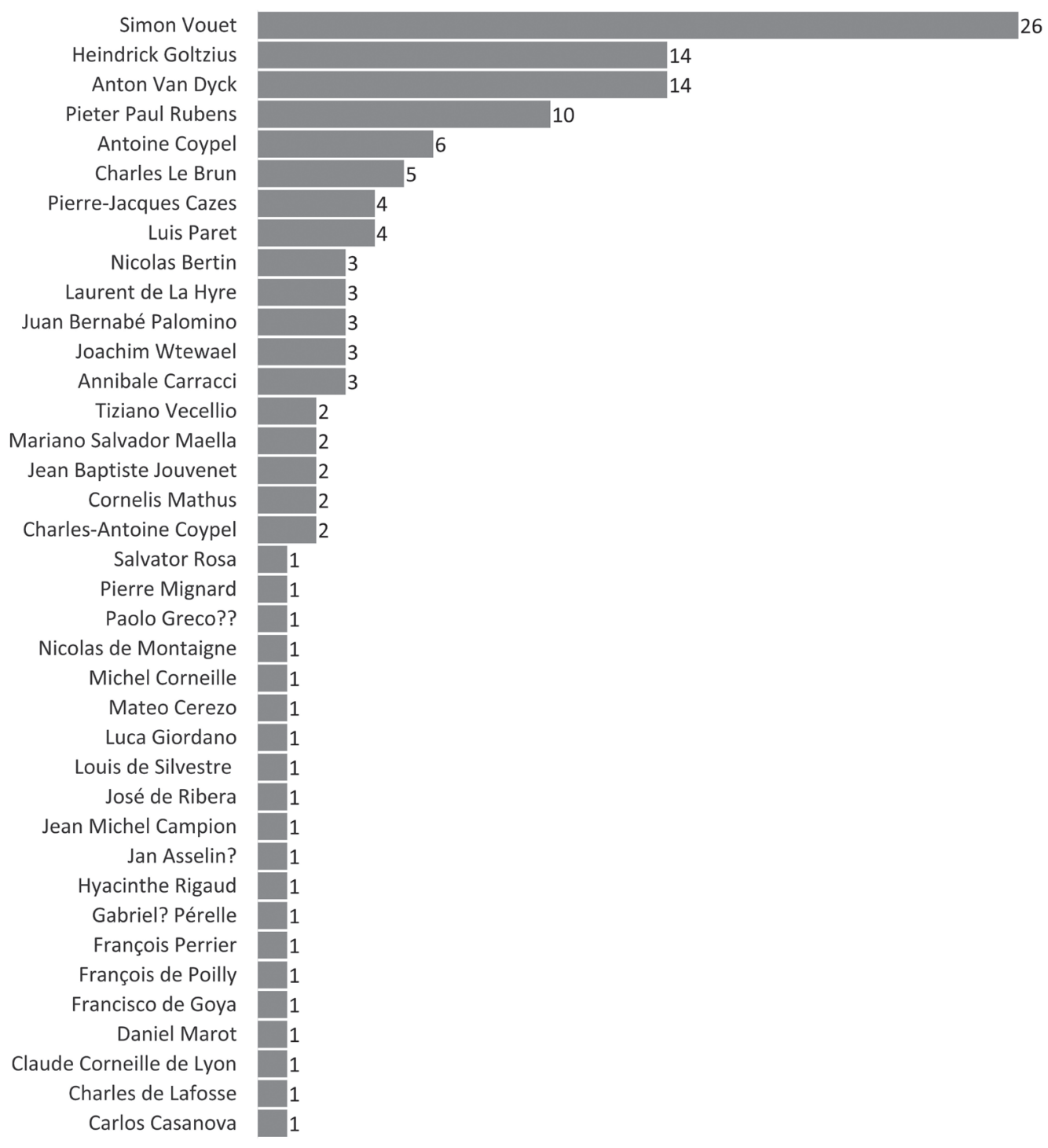

Fig. 1. Distribución de las estampas de Domingo de Rada según autores (Elaboración propia)

(fig. 2). La escena representa a Hércules o Alcides que se sitúa en lo alto de una roca, mientras el pueblo se arremolina en torno a él. En la composición de Rada, la figura está representada de forma similar, sentada, con la pierna derecha en escorzo y el brazo derecho sobre ella, apoyando la cabeza en la mano con el dedo índice sobre ella. También son similares la túnica extendida sobre las piernas y el brazo izquierdo extendido. Sin embargo, se modifica la postura de arenga de Hércules por el gesto de mostrar un cáliz con una serpiente en su interior.

En cambio, otros dos de los Evangelistas, San Lucas y San Marcos, están basadas en

Allouard Libraire-Bouchard Huzard Libraire, París, 1839, p. 281. obras de Rubens, en concreto, en dos grabados de Jan de Punt que reproducen las pinturas del techo de la Iglesia de los Jesuitas de Amberes, grabados presentes en el inventario de Rada. Domingo tomó como modelo para San Lucas Evangelista a Jesús tentado por el demonio (fig. 3) y a San Jerónimo Penitente como modelo para San Marcos Evangelista (fig. 4).

Como se ve, Rada no elige para la composición imágenes que ya representaran a evangelistas, a pesar de que existían estampas con esa temática en su colección. En ese sentido, es posible que eligiera los modelos de Rubens porque siguen una perspectiva sotto in sú, ya que están pensadas para unos techos. Esta perspectiva resulta muy apropiada para representarse en unas pechinas, pensadas para ser vistas desde abajo. 

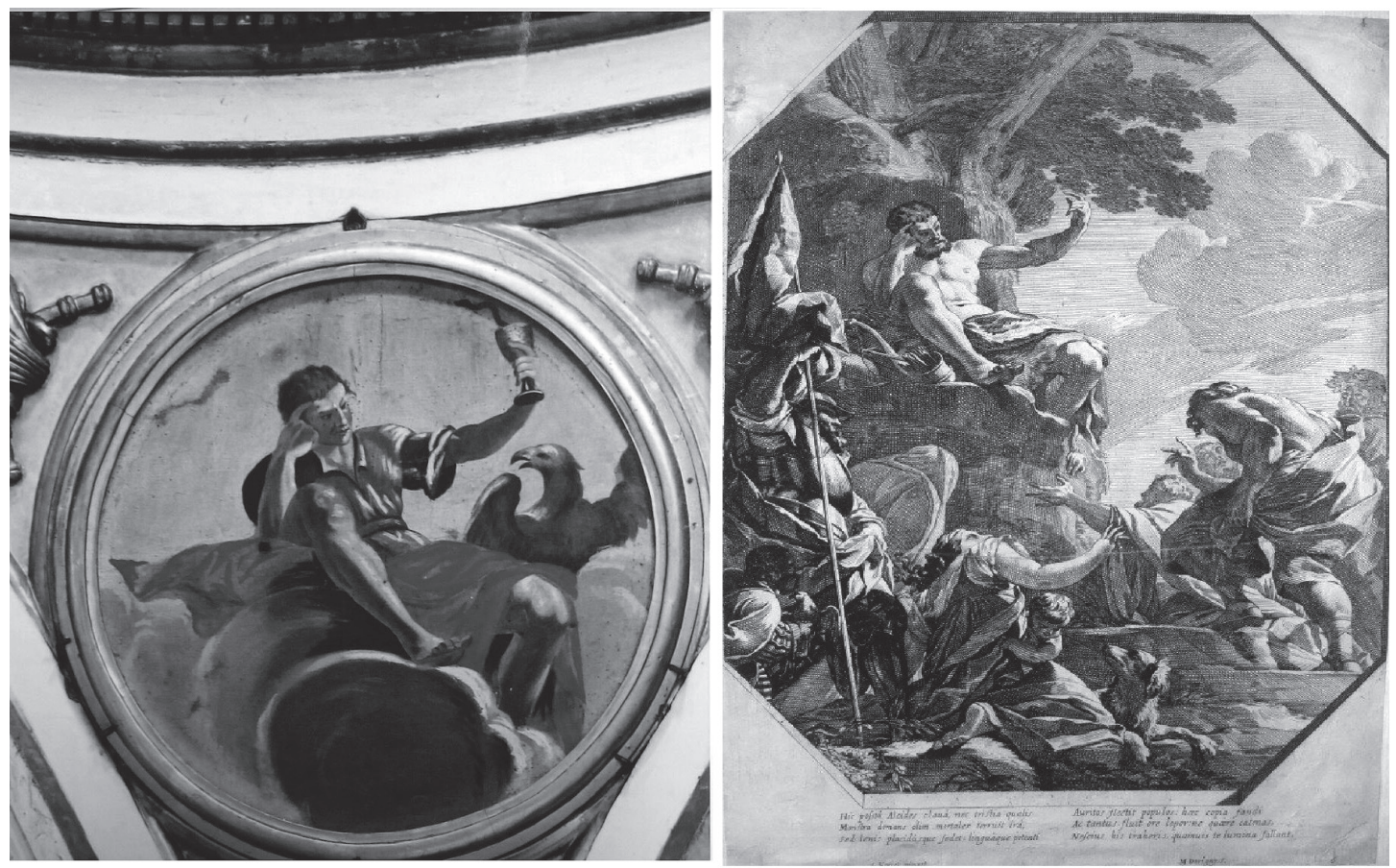

59

Figura 2. Domingo de Rada, San Juan evangelista, hacia 1774, Calahorra, Iglesia de Santiago, crucero, pechina sureste de Rada (fotografía de Pablo Díaz Bodegas) y Simón Vouet (original), Michel Dorigny (grabador), Alcides, Londres, British Museum, n 1841,1211.39.92. Fuentes: Pablo Díaz Bodegas y British Museum (https://goo.gl/aUhjDp).
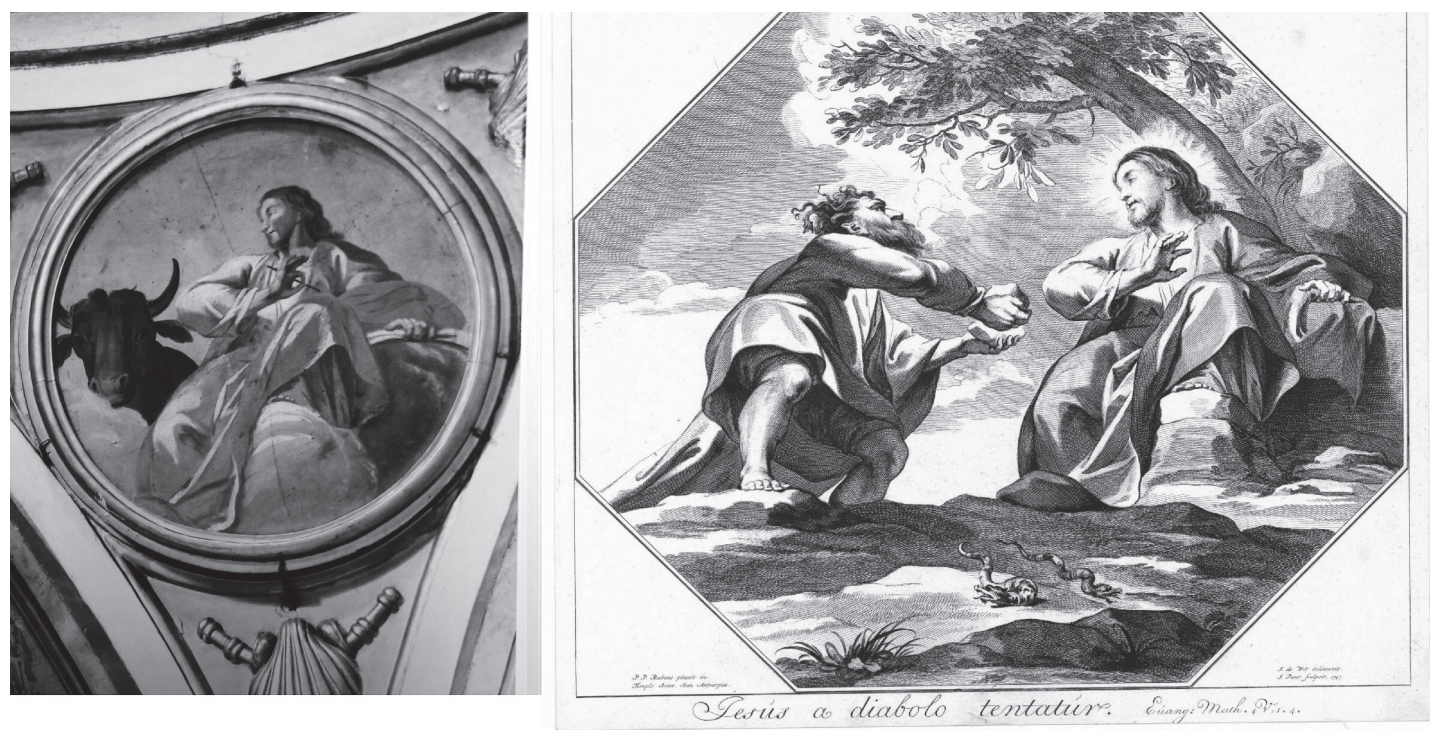

Fig. 3. Domingo de Rada, San Lucas evangelista, hacia 1774, Calahorra, Iglesia de Santiago, crucero, pechina nordeste de Rada (fotografía de Pablo Díaz Bodegas) y Pedro Pablo Rubens (original), Jacob de Wit (dibujo), Jan Punt (grabador), Jesús tentado por el diablo, Londres, British Museum, n 1875,0710.2981. Fuentes: Pablo Díaz Bodegas y British Museum (https://goo.gl/L33vho)

Además, elegir la figura de San Jerónimo permitía a Rada aprovechar la representación del león para la figura de San Marcos. Igualmente, la figura de Alcides aparece sentada, en un escorzo que aporta sensación de profundidad, e igualmente situado en lo alto. En este caso, al utilizar el modelo de Vouet para San Juan conlleva convertir una escena mitológica en una escena religiosa, pero no se trata de una elección extraña: Requena analiza cómo Juan de Sevilla ya en el siglo xvII toma una escena de Vouet que representaba a Venus para convertirla en una Sagrada Familia ${ }^{45}$.

45 REQUENA BRAVO DE LAGUNA, José Luis, "Nuevas fuentes grabadas...", opus cit. 

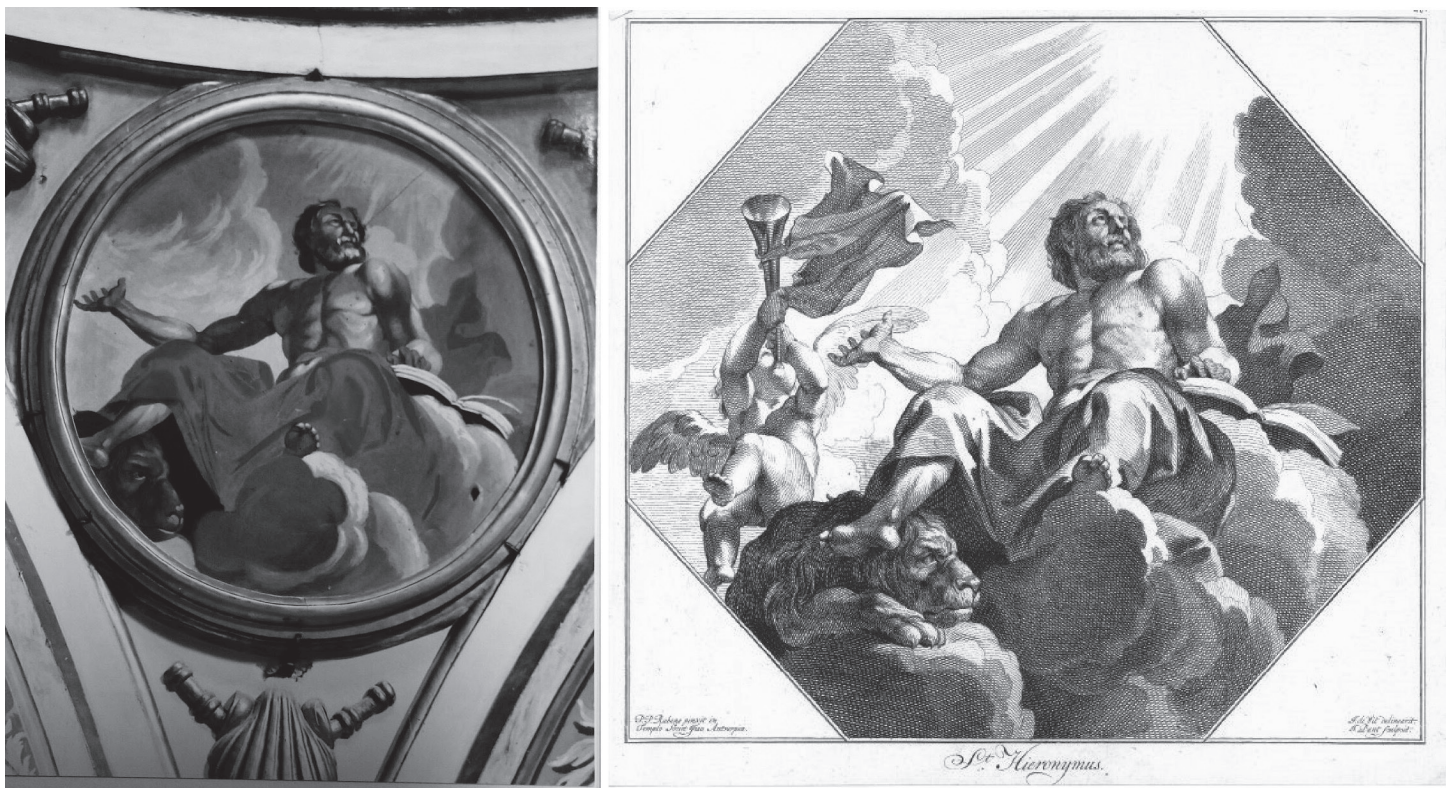

Fig.4. Domingo de Rada, San Marcos evangelista, hacia 1774, Calahorra, Iglesia de Santiago, crucero, pechina noroeste de Rada (fotografía de Pablo Díaz Bodegas) y Pedro Pablo Rubens (original), Jacob de Wit (dibujo), Jan Punt (grabador), San Jerónimo, Londres, British Museum, no 1875,0710.3005. Fuentes: Pablo Díaz Bodegas y British Museum (https://goo.gl/bfcoEu).

En otra pintura realizada por Rada para la ciudad de Calahorra, aunque en este caso para la catedral de San María, se aprecia una representación de San Juanito y el Niño Jesús que en esta ocasión parece inspirada en dos obras del grabador Hendrick Goltzius, diseñadas e impresas por él mismo, que representan un mismo tema alegórico: Quis evadet, sobre la fugacidad de la vida ${ }^{46}$, y que muestran a dos niños sobre una calavera haciendo pompas de jabón. A pesar de la diferencia temática, la postura de sus cabezas y extremidades así como los rizos y los rasgos de la cara son muy similares en las estampas y la pintura; solo la postura de las piernas difiere ligeramente. Eso sí, para que los niños aparecieran mirándose entre sí, Rada ha girado una de las estampas $180^{\circ}$ (fig. 5).

Las otras dos obras realizadas por Rada, las pinturas para los retablos de Busturia-Axpe, se sitúan ya en una fecha tardía, hacia 1792, y cuando Domingo llevaba años trabajando como profesor de la Escuela de Dibujo de Bilbao. Sin embargo, los modelos que utiliza siguen siendo fundamentalmente barrocos, aunque en esta ocasión opta por obras de autores italianos y españoles: Zorrozua, que ha estudiado estas obras, indica cómo para la representación de San

46 Estas obras no aparecen citadas con este título en el inventario de Rada, aunque éste recoge varias "fábulas" de Goltzius que podrían corresponder a temas alegóricos.
Miguel Arcángel se inspiró en los modelos de Guido Reni ${ }^{47}$. A esto podemos añadir que para el cuadro del retablo gemelo, que representa a Santiago Matamoros, tomó parte de la composición de una estampa según modelo de Luca Giordano que poseía en su colección, y que representaba la Victoria de los Reyes Católicos.

\section{Discusión de los resultados}

El análisis de la colección de estampas y de la obra pictórica de Domingo de Rada muestran, por lo tanto, la influencia de modelos franceses, en especial de Simon Vouet, el autor más presente en su inventario de estampas e inspiración para, al menos, una de sus obras. El estudio de su biografía nos permite, además, intuir la vía por la que Rada pudo llegar al conocimiento e interés por Vouet. Gutiérrez Pastor, gran conocedor del panorama pictórico riojano del siglo XVIII, afirma que el primer autor en copiar modelos de Vouet en esta región fue José Bejes, hacia 1757: "Bejes hizo uso por primera vez en La Rioja de estampas que reproducen las composiciones francesas de Simon Vouet" ${ }^{48}$. Y

$\overline{47}$ ZORROZUA, Julen, “Las artes figurativas...”, opus cit., p. 66.

48 GUTIÉRREZ PASTOR, Ismael, "La pintura del siglo XVIII", opus cit., p. 390. 

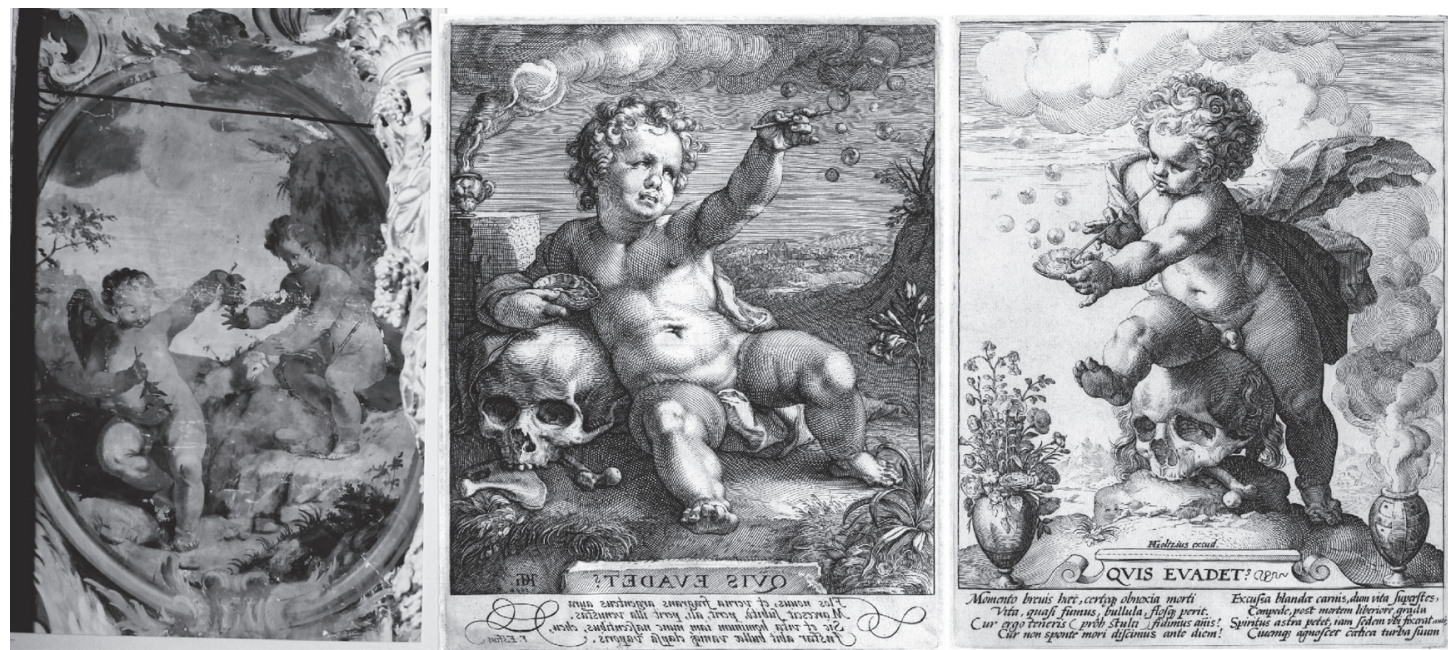

Fig. 5. Domingo de Rada, San Juanito y el Niño Jesús, hacia 1775, Calahorra, Iglesia catedral de Santa María, pies de la iglesia, capilla de San Juan Bautista (fotografía de Pablo Díaz Bodegas) y Heindrik Goltzius, Quis evadet?, Londres, British Museum, $\mathrm{n}^{\circ} 1875,0710.3005$. Fuentes: Pablo Díaz Bodegas y British Museum (https://goo.gl/bfcoEu).

añade más adelante que en la localidad riojana de Alberite "es donde vuelven a aparecer una serie de composiciones que Bejes toma prestadas de otros pintores, bien directamente, bien a través de estampas de Simon Vouet para la Sagrada Familia"49. Como ya hemos indicado, Rada tuvo contacto con Bejes en Calahorra, y posiblemente volvieran a coincidir tras el viaje de este último a Bilbao. A lo que podemos añadir que, al redactar testamento, Rada nombró como su albacea testamentario a Joaquín de Bejes, hijo de Bejes y presbítero beneficiado en Santa María de Palacio ${ }^{50}$. Existe, por tanto, la posibilidad de que fuera a través de Bejes como Rada conoció la figura de Vouet y se impregnó de su influencia.

Además, es posible que la inclinación hacia los modelos franceses se afianzara aún más durante su estancia en Bilbao, una región abierta a las influencias atlánticas y con frecuentes relaciones comerciales con el ámbito francés. Por citar un ejemplo, la Escuela de Dibujo en la que Rada trabajaba, a pesar de haberse inspirado bastante en la Real Academia de San Fernando para su constitución, tomó también como modelo la Academia francesa, mostrando una gran inclinación hacia lo francés en los modelos que proponía a sus alumnos ${ }^{51}$. De hecho, entre las

49 GUTIÉRREZ PASTOR, Ismael, "La pintura del siglo XVIII", opus cit., p. 397.

50 AHPLR, Protocolos notariales, Logroño, leg. 1136, 1806, fol. 210r.-211v.

51 RUIZ DE AEL, Mariano J., "Las escuelas de dibujo del País Vasco en el siglo XviII: sus modelos académicos”, estampas que la Escuela poseía, se encontraban autores como Perelle, Poilly, Silvestre, Rubens, Le Brun, Carracci, Rigaud, Hyre y Goltzius ${ }^{52}$, presentes también en la colección de Rada. Y Ruiz de Ael indica expresamente que "los modelos de grabadores franceses (...) son los que predominan de manera aplastante sobre los modelos italianos (...) Al parecer los ilustrados vascos se sentían mucho más identificados con los modelos franceses que con los procedentes de nuestra península"53. En este sentido, es llamativo que, al ser contratado como profesor en la Escuela de Dibujo de Logroño, Rada recomendara la adquisición de modelos de un pintor francés, aún vivo y poco presente entre los artistas de referencia recomendados por la Real Academia de San Fernando: Jacques-Louis David ${ }^{54}$

Otra influencia que pudo inclinar a Rada hacia los modelos franceses fue su trato con el pintor Luis Paret, con quien colaboró en las pinturas del Ayuntamiento de Bilbao. Ese encuentro debió de marcar significativamente a Rada: conservó entre sus estampas varios dibujos y grabados de Paret, y posiblemente fuera influido por el estilo cortesano del pintor ma-

en Sancho el sabio: Revista de cultura e investigación vasca, 3, Logroño, 1993, pp. 149-164, en https://dialnet.unirioja.es/descarga/articulo/157521.pdf.

52 RUIZ DE AEL, Mariano J., La ilustración artística, opus cit., pp. 173-174.

53 RUIZ DE AEL, Mariano J., La ilustración artística, opus cit., p. 176.

54 MARTÍNEZ OCIO, María Jesús, "La Escuela de Dibujo", opus cit., p. 148. 
drileño, muy deudor del rococó francés por su ascendencia francesa ${ }^{55}$.

Sin embargo, en la línea de la hipótesis de Vélez Chaurri ${ }^{56}$, lo cierto es que, a pesar de su vinculación con iniciativas academicistas, Rada mantuvo entre sus estampas los modelos flamencos de autores como Van Dyck, Rubens y Goltzius, estos últimos utilizados como inspiración para las obras realizadas en la década de 1770 (fig. 3, 4 y 5). Y no es el único ejemplo: también en el ya citado José Bejes, Gutiérrez Pastor aprecia una fuerte influencia de "las estampas flamencas de las obras de Rubens”, por lo que en él se aprecia simultáneamente la influencia de Vouet y la influencia flamenca ${ }^{57}$.

Todo esto demuestra que en La Rioja y País Vasco los modelos franceses no sustituyeron a los modelos flamencos como fuente de inspiración para pintores y escultores de finales del siglo XVIII y principios del siglo xIX, sino que convivieron en el tiempo, evidenciando la lentitud de los cambios de paradigmas artísticos en la época.
55 VV.AA., Luis Paret y Alcázar, 1746-1799, Gobierno Vasco - Departamento de Cultura, Vitoria, 1991.

56 VÉLEZ CHAURRI, José Javier, "La estampa rubeniana”, opus cit., p. 223.

\footnotetext{
7 GUTIÉRREZ PASTOR, Ismael, "La pintura del siglo XVIII", opus cit., p. 387.
} 